\title{
A Low-Carbon Generation Expansion Planning Model Considering Carbon Trading and Green Certificate Transaction Mechanisms
}

\author{
Yuansheng Huang, Jianjun Hu, Yingqi Yang, Lei Yang, Shijian Liu* \\ Department of Economics and Management, North China Electric Power University, Baoding, China
}

Received: 17 January 2019

Accepted: 28 March 2019

\begin{abstract}
Generation expansion planning for more renewable energy is of great significance to the implementation of low-carbon economy and energy transition in the power sector. This paper introduces two widely used renewable energy incentives (such as carbon trading mechanism and green certificate transaction mechanism) into traditional generation expansion planning, and establishes a low-carbon generation expansion planning model. Then the brain storm optimization algorithm was employed to solve the model. Finally, for the comparison between the two mechanisms, this paper sets four scenarios for case simulation. The results show that both carbon trading mechanisms and green certificate transaction mechanisms can increase the installed capacity of renewable energy and reduce carbon emissions, and the optimization effect of green certificate transaction mechanism on planning results is better than that of the carbon trading mechanism. When both mechanisms are introduced, the installed proportion of renewable energy will be the highest and carbon emissions will achieve the minimum. Moreover, with the increase of carbon price or green certificate price, and the strengthening of carbon emission constraint or renewable energy quota constraint, the proportion of coal-fired units in the power supply structure is gradually decreasing, and the carbon emissions of the system are gradually reduced.
\end{abstract}

Keywords: generation expansion planning, carbon trading mechanism, green certificate transaction mechanism, fuzzy chance constraints, brain storm optimization

\section{Introduction}

In recent years, global warming caused by the massive emission of greenhouse gases has brought a series of negative impacts on the living environment of human beings, which is an urgent problem for human

*e-mail: 1172106017@ncepu.edu.cn society [1]. China's $\mathrm{CO}_{2}$ emissions are currently ranked first in the world. In particular, the power industry's $\mathrm{CO}_{2}$ emissions account for more than $40 \%$ of the total national emissions [2]. One of the main ways for the power sector to achieve carbon emission reduction targets is to prioritize the development of renewable energy and reduce the use of fossil fuels in generation expansion planning [3-6]. As a consequence, generation expansion planning plays a key role for the achievement of more renewable energy and low $\mathrm{CO}_{2}$ emissions objectives in an efficient and effective way. 
Traditional generation expansion planning takes the minimum investment and operating costs during the planning period as the sole criterion [7-10]. With the increasingly serious environmental problems and people's awareness of environmental protection, traditional generation expansion planning has been unable to meet the requirements of social development and has gradually shifted to a low-carbon direction [11-12]. In the generation expansion planning for lowcarbon targets, scholars have paid more attention to a variety of low-carbon elements, including the use of renewable energy generation technologies and the implementation of renewable energy incentives, all of which have profound impacts on traditional generation expansion planning.

Some scholars have introduced renewable energy generation technologies such as photovoltaic plants, hydropower units, wind turbines, and biomass units into the generation expansion planning model. For example, Jayapalan et al. [13] considered the wind and solar energy sources as the candidates with conventional power plants and fund the most optimal generation capacity expansion planning. Gitizadeh et al. [14] studied the issue of generation expansion planning including onshore wind, offshore wind, solar and other renewable energy power plants. Aghaei et al. [15] considered multiple renewable energy sources to establish a multi-objective generation expansion planning model with minimum cost, emissions, energy consumption, investment risk and maximum system reliability, and adopted fuzzy decision-making methods to obtain the optimal solution. Jain et al. [16] studied the allowable access range of wind DGs, and provided a scientific decision basis for wind DGs to access generation expansion planning. Kaabeche et al. [17] focused on the development of an optimal sizing model to optimize the capacity sizes of various stand-alone $\mathrm{P}$ V/wind/diesel/battery hybrid system components.

To achieve more installed capacity for renewable energy, the government's measures are needed, such as the carbon trading mechanism [18-21] and the green certificate transaction mechanism [22-25]. The essence of the carbon trading mechanism is to trade carbon emission permits as a commodity, and encourage enterprises to engage in carbon emission reduction activities, thereby achieving the goal of reducing carbon emissions. Currently, it has been widely used in most developed countries. The introduction of a carbon trading mechanism will undoubtedly have an impact on traditional generation expansion planning. Zhu et al. [26] developed a dynamic optimization method to planning MEPS (municipal electric power systems) of Beijing, and carbon trading has been introduced into MEPS for mitigating $\mathrm{CO}_{2}$ emissions. In addition, $\mathrm{Zhu}$ et al. [27] also developed a risk-explicit mixed-integer fullinfinite programming (RMFP) approach for planning carbon trading in electric power systems. UnsihuayVila et al. [28] established a multi-objective, multiregion and multi-stage generation expansion planning model, focusing on a clean development mechanism and European Union greenhouse gas emission trading scheme. Tan et al. [29] established an integrated optimization model to study the impacts of clean energy and carbon trading mechanism on inter-regional energy exchange.

Similar to the carbon trading mechanism, the green certificate transaction mechanism aims to promote the adjustment of energy structures. The difference is that the carbon trading mechanism is mainly to reduce $\mathrm{CO}_{2}$ emissions, while the green certificate transaction mechanism is to promote the development of renewable energy. Bergek et al. [30] have shown that the introduction of green certificate transaction mechanisms will promote technological progress and industrial transformation in the power sector. Qin et al. [31] further discussed the positive effects of green certificate transaction mechanisms on promoting the proportion of renewable energy in China. Park et al. [32] present a stochastic generation expansion planning model to investigate the changes in generation building decisions and $\mathrm{CO}_{2}$ emissions under environmental energy policies, including carbon tax and green certificate transaction mechanisms. Geem et al. [33] proposed an optimal energy mix planning model in electricity generation from various energy sources, such as gas, coal, nuclear, hydro, wind, photovoltaic, and biomass, which considers more renewable portions by imposing renewable portfolio standards.

Generation expansion planning is a multi-variable, multi-objective and multi-stage nonlinear dynamic optimization problem. There is currently no strict unified algorithm. In recent years, more and more swarm intelligence algorithms have been introduced into generation expansion planning. Among them, genetic algorithm (GA) and particle swarm optimization (PSO) have been widely used. Pereira et al. [34-36] used genetic algorithm to optimize the scale of a hybrid renewable energy system. However, this method has the disadvantages of long computation time, overcomplexity and occasionally calculating local optimal solutions. Ganguly et al. [37-41] optimized the installed capacity of hybrid renewable energy systems by particle swarm optimization, which has strong global optimization ability, but its local search ability is relatively poor. Based on the idea of solving problems creatively by human beings, Shi [42-43] proposed a new swarm intelligence algorithm, brain storm optimization (BSO), in 2011. A human being is the smartest animal in the world, and the BSO algorithm inspired by its social behavior is considered to be a promising method. In the low-carbon generation expansion planning problem, BSO has the advantage of searching global optimal values in parallel. It can find the optimal fitness value within the range of small iterations and the specified accuracy requirements. Therefore, the BSO algorithm is used to optimize the model in this paper.

This paper aims to propose a low-carbon generation expansion planning model that takes into account 
the economic, low-carbon and reliability of the system, and contributes to the previous literature in this field: (i) building the optimization model for generation expansion planning considering carbon trading mechanism and green certificate transaction mechanism; (ii) using fuzzy chance constraints to address the problem of the multiple uncertainties for load forecasting, wind power output and photovoltaic power output; (iii) adopting the BSO algorithm to solve the low-carbon generation expansion planning model. The results will help decision makers guide the optimization of power source structure in the power sector.

The structure of this paper is organized as follows: In Section 2, a low-carbon generation expansion planning model is constructed. Section 3 briefly introduces the BSO algorithm and Section 4 shows details of the case study data. In Section 5, BSO, PSO and GA are respectively adopted to solve the low-carbon generation expansion planning model, and the results are compared. In Section 6, the results obtained by BSO algorithm are explained and discussed.

\section{Modeling Formulation}

\section{Objective Function}

The traditional generation expansion planning model takes the minimum investment cost and operating cost of the system during the planning period as the objective function, and does not consider environmental issues such as carbon emissions. This paper introduces the carbon trading mechanism and the green certificate transaction mechanism widely used in developed countries into generation expansion planning, taking into account investment cost, operating cost, carbon trading cost and green certificate transaction cost, and a low-carbon generation expansion planning model with the minimum system economic cost as the objective function is established. The objective function is defined as follows:

$$
C=\sum_{t=1}^{T}\left(C_{i}^{t}+C_{o}^{t}+C_{g}^{t}+C_{c o_{2}}^{t}\right)
$$

...where $C$ is the total cost during the planning period; $T$ is the planning period; $C_{i}^{t}$ is the investment cost at year $t ; C_{o}^{t}$ is the operating cost at year $t ; C_{\mathrm{CO}_{2}}^{t}$ is the carbon trading cost at year $t ; C_{g}{ }^{t}$ is the green certificate transaction cost at year $t$.

\section{Investment Cost}

The service life of different types of units is not the same. For the convenience of calculation, this paper adopts the equal annual value method to convert the static investment cost of the units into the equivalent annual investment cost.

$$
C_{i}^{t}=\sum_{i \in \Omega_{\text {new }}} I_{i} D_{i t} \frac{r(1+r)^{n_{i}}}{(1+r)^{n_{i}}-1}
$$

...where $\Omega_{\text {new }}$ is the collection of units to be built; $I_{i}$ is the static investment cost of unit $i$; the value of $D_{i t}$ is a 0 or 1 , when $D_{i t}=1$, it means that the unit $i$ is to be built at year $t$, when $D_{i t}=0$, it means that the unit $i$ is not to be built at year $t ; n_{i}$ is the service life of unit $i ; r$ is the discount rate.

\section{Operating Cost}

The operating cost of the unit at year $t$ is:

$$
C_{o}^{t}=\sum_{i=1}^{N} C_{i} E_{i t}
$$

...where $N$ is the number of units already built at year $t$, $C_{i}$ is the operating cost of unit $i$, and $E_{i t}$ is the generating capacity of unit $i$ at year $t$.

\section{Carbon Trading Cost}

Carbon trading mechanism is essentially an important mechanism for reducing carbon emissions from a power system through the trading of carbon emission permits. There are two primary allocation methods for carbon emission permits that are widely used at present: free distribution and paid distribution. For power generation companies, the use of a paid distribution method will increase the cost of the company, so the company will have a conflicting attitude, while the free distribution method is relatively moderate and easy to implement. Therefore, this paper adopts the method of freely assigning initial carbon emission permits, and the carbon trading cost can be expressed as:

$$
C_{c o_{2}}^{t}=\sum_{i=1}^{N} P\left(K_{i t} E_{i t}-\eta_{i}^{c o_{2}} E_{i t}\right)
$$

...where $P$ is the carbon price, $K_{i t}$ is the carbon emission intensity of unit $i$ at year $t$, and $\eta_{i}{ }^{C O_{2}}$ is the carbon cap per unit of electricity.

\section{Green Certificate Transaction Cost}

In order to promote the development of renewable energy, developed countries have proposed the renewable portfolio standard (RPS), which is essentially an incentive mechanism to promote energy development and utilization. The implementation of this standard must be completed through the green certificate transaction mechanism. The quota is generally expressed as the proportion of the generating capacity of renewable energy units to the total generating capacity, 
and the generating capacity of renewable energy units is converted into a certain number of green certificates. Determine profit or pay costs based on the company's actual generating capacity and the regulatory agency's established renewable energy quotas. The green certificate transaction cost can be expressed as:

$$
C_{g}^{t}=-v_{g}^{t} k^{g}\left(\sum_{i \in \Omega^{r e}} E_{t}-E \eta_{t}^{g}\right)
$$

...where $v_{g}^{t}$ is the green certificate price at year $t ; k^{g}$ is the quantitative coefficient that converts renewable energy generation into a certain amount of green certificates; $\Omega^{r e}$ is the collection of renewable energy units; and $\eta_{g}^{t}$ is the renewable energy quota coefficient.

\section{Constraints}

\section{Power Balance Constraint}

Under a certain confidence level, the sum of the unit's output at year $t$ of the system shall not be less than the maximum load demand of that year:

$$
\operatorname{Cr}\left\{\sum_{i=1}^{N_{C}} P_{C i}+\sum_{i=1}^{N_{P V}} P_{P V i}+\sum_{i=1}^{N_{W T}} P_{W T i}-P_{t} \geq 0\right\} \geq \alpha
$$

...where $P_{C i}, P_{P V i}$, and $P_{W T i}$ are the output of conventional units, wind turbines, and photovoltaic plants; $N_{C}, N_{P \text { r }}$, and $N_{W T}$ are the number of conventional units, wind turbines, and photovoltaic plants at year $t ; P_{t}$ is the maximum load demand of the system at year $t$; and $\alpha$ is the confidence level.

Load forecasting, wind power output and photovoltaic power output are uncertain. In order to ensure the reliability of power supply, the installed capacity of the power system should not only meet the load demand, but also have a certain reserve capacity. However, the power reserve ratio is not included in the formula because the uncertainty factors have been considered in the fuzzy chance constraints.

\section{Electric Quantity Balance Constraint}

During the planning period, the annual generating capacity of the system should meet the electricity demand for that year:

$$
\sum_{i=1}^{N} E_{i t} \times\left(1-\varepsilon_{i t}\right)\left(1-\delta_{t}\right)=D_{t}
$$

...where $\varepsilon_{i t}$ is the station service power consumption rate of unit $i$ at year $t, \delta_{i t}$ is the line loss rate at year $t$, and $D_{t}$ is the electricity demand at year $t$.

\section{Unit Output Constraint}

The output of the unit is limited to a certain range:

$$
h_{i} \gamma_{t, \text { min }} \beta_{i} P_{i} \leq E_{i} \leq h_{i} \beta_{i} P_{i}
$$

...where $h_{i}$ is the annual utilization hours of unit $i ; \gamma_{i, \text { min }}$ is the minimum output coefficient of unit $i ; \beta_{i}$ is the availability factor of unit $i$, and $\beta_{i}=1$-forced outage rate; and $P_{i}$ is the output of unit $i$ at year $t$.

\section{Installed Capacity Constraint}

Due to the constraints of technology, policies, funds, etc., the installed capacity of the newly commissioned units of the system cannot exceed the maximum limit capacity each year:

$$
0 \leq P_{i t} \leq P_{i t, \max }
$$

...where $P_{i t, \max }$ is the maximum limit capacity of unit $i$ at year $t$.

\section{Handling of Fuzzy Chance Constraints}

There are many uncertainties in the process of generation expansion planning. If these uncertainties are ignored, the optimal solution obtained may no longer maintain optimal. As a result, the generation expansion planning result deviates from the actual situation, which adversely affects the power quality and power supply reliability of the system. Therefore, the uncertainties should be fully considered in the generation expansion planning to make the planning results realistic [44]. This paper considers the ambiguity of the system's maximum load, wind power output and photovoltaic power output, and uses fuzzy chance constraints to transform these uncertain factors into deterministic factors.

The fuzzy parameters of the system's maximum load, wind power and photovoltaic power output during the planning period can be represented by a trapezoidal function [45]:

$$
\mu\left(P_{F}\right)=\left\{\begin{array}{c}
\frac{P_{F 4}-P_{F}}{P_{F 4}-P_{F 3}}, P_{F 3} \leq P_{F} \leq P_{F 4} \\
1, P_{F 2} \leq P_{F} \leq P_{F 3} \\
\frac{P_{F}-P_{F 1}}{P_{F 3}-P_{F 1}}, P_{F 1} \leq P_{F} \leq P_{F 2} \\
0, \text { others }
\end{array}\right.
$$

...where $\mu\left(P_{F}\right)$ is the trapezoidal membership function, and $P_{F}(i=1,2,3,4)$ are the trapezoidal membership parameters.

$P_{F}$ can be determined by the predicted value $P^{\text {forecast }}$. 


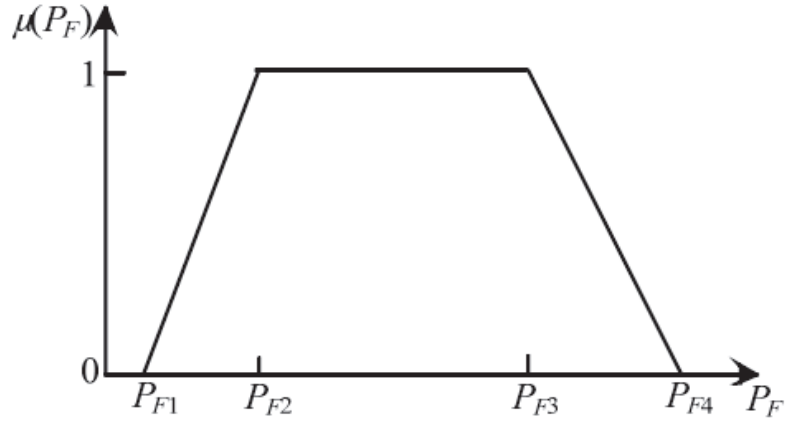

Fig 1. Trapezoidal fuzzy parameters.

$$
P_{F i}=\omega_{i} P^{\text {forecast }}
$$

...where $\omega_{i}(i=1,2,3,4)$ are the scale factors.

Then the trapezoidal fuzzy parameters can be expressed as:

$$
P_{F}=\left(P_{F 1}, P_{F 2}, P_{F 3}, P_{F 4}\right)=\left(\omega_{1}, \omega_{2}, \omega_{3}, \omega_{4}\right) P^{\text {forecast }}
$$

The trapezoidal fuzzy parameters are shown in Fig. 1.

At present, there are two main methods to deal with fuzzy chance constraints: fuzzy simulation method and clear equivalence class method. The clear equivalence class method is convenient to convert and suitable for solving models [46]. This paper uses this method to transform the fuzzy chance constraint into its clear equivalence class.

Assume that the constraint is the following form:

$$
g(x, \xi)=h_{1}(x) \xi_{1}+h_{2}(x) \xi_{2}+\mathrm{L}+h_{t}(x) \xi_{t}+h_{0}(x)
$$

...where $\xi_{k}$ are the trapezoidal fuzzy parameters $\left(r_{k 1}, r_{k 2}\right.$, $\left.r_{k 3}, r_{k 4}\right), k=1,2, \ldots t, t \in R$ and $r_{k 1}-r_{k 4}$ are the membership parameters.

Define two functions:

$$
\begin{gathered}
h_{k}^{+}(x)=\left\{\begin{array}{c}
h_{k}(x), h_{k}(x) \geq 0 \\
0, h_{k}(x)<0
\end{array}\right. \\
h_{k}{ }^{-}(x)=\left\{\begin{array}{c}
0, h_{k}(x) \geq 0 \\
-h_{k}(x), h_{k}(x)<0
\end{array}\right.
\end{gathered}
$$

$h_{k}^{+}(x)$ and $h_{k}^{-}$need to satisfy:

$$
h_{k}(x)=h_{k}^{+}(x)-h_{k}^{-}(x)
$$

Particularly, if $h(x)=1$, then $h^{+}(x)=1, h^{-}(x)=0$; if $h(x)=-1 h^{+}(x)=0, h^{-}(x)=1$. So: $g(x, \xi)=\sum_{k=1}^{t}\left[h_{k}^{+}(x)-h_{k}^{-}(x) \xi_{k}=\sum_{k=1}^{t}\left[h_{k}^{+}(x) \xi_{k}-h_{k}^{-}(x) \xi_{k}^{\prime}\right]\right.$

..where $\xi_{k}^{\prime}=\left(-r_{k 4},-r_{k 3},-r_{k 2},-r_{k 1}\right)$.

According to the algorithm of the trapezoidal fuzzy number, we can get:

$$
\begin{aligned}
& g(x, \xi)=\left(\sum_{k=1}^{t}\left[r_{k 1} h_{k}^{+}(x)-r_{k 4} h_{k}^{-}(x)\right], \sum_{k=1}^{t}\left[r_{k 2} h_{k}^{+}(x)-r_{k 3} h_{k}^{-}(x)\right]\right. \\
& \left.\sum_{k=1}^{t}\left[r_{k 3} h_{k}^{+}(x)-r_{k 2} h_{k}^{-}(x)\right], \sum_{k=1}^{t}\left[r_{k 4} h_{k}^{+}(x)-r_{k 1} h_{k}^{-}(x)\right]\right)
\end{aligned}
$$

When $(1-\alpha) r_{1}+\alpha r_{2} \leq 0, \operatorname{Cr}\{g(x, \xi) \leq 0\} \geq \alpha$ is true for any confidence level $\alpha$. Therefore, when the confidence level of the fuzzy chance constraint $\alpha \leq 0.5$, the clear equivalence class of $\operatorname{Cr}\{g(x, \xi) \leq 0\} \geq \alpha$ is:

$$
\begin{gathered}
(2-2 \alpha) \sum_{k=1}^{t}\left[r_{k 3} h_{k}^{+}(x)-r_{k 2} h^{-}(x)\right]+(2 \alpha-1) \\
\sum_{k=1}^{t}\left[r_{k 4} h_{k}^{+}(x)-r_{k 1} h_{k}^{-}(x)\right]+h_{0}(x) \leq 0
\end{gathered}
$$

In this paper, the annual maximum load of the system is represented by the trapezoidal fuzzy number $\left(P_{1}, P_{2}, P_{3}, P_{4}\right)$, the wind power output is represented by the trapezoidal fuzzy number $\left(P_{W T 1}, P_{W T 2}, P_{W T 3}\right.$, $\left.P_{W T 4}\right)$, and the photovoltaic power output is represented by the trapezoidal fuzzy number $\left(P_{P V 1}, P_{P V 2}, P_{P V 3}\right.$, $\left.P_{P V 4}\right)$. Using the above-mentioned processing method for fuzzy chance constraints, the system's power balance constraint is transformed into its clear equivalence class:

$$
\begin{gathered}
(2-2 \alpha)\left[\omega_{3} P_{3}-\sum_{i=1}^{N_{V}} \omega_{2} P_{P V i_{2}}-\sum_{i=1}^{N_{W}} \omega_{2} P_{W T i_{2}}\right]+(2 \alpha-1) \\
{\left[\omega_{4} P_{4}-\sum_{i=1}^{N_{F}} \omega_{1} P_{P V i_{1}}-\sum_{I=1}^{N_{W}} \omega_{1} P_{W T i_{1}}\right]-\sum_{i=1}^{N_{C}} P_{C} \leq 0}
\end{gathered}
$$

\section{Brain Storm Optimization (BSO)}

The brainstorming method was first proposed by Alex F. Osborn in 1939 and was used as a creative solution to problems. The central idea of this method is to gather a group of people with different backgrounds to speak freely around a specific topic, and finally form the best solution to solve the problem through the exchange of ideas. There are four basic guidelines for brainstorming:

(1) Any ideas of the brainstorming group members around the topic can be raised. 
(2) All ideas cannot be judged until the end of a round of meetings.

(3) Many new ideas are generated from existing ideas.

(4) Generate as many new ideas as possible, and then select from a large number of ideas to obtain the optimal solution.

Based on the idea of creative problem solving in brainstorming sessions, Shi proposed a new group intelligent optimization algorithm, brain storm optimization algorithm (BSO), in the Second International Conference on Swarm Intelligence (ICSI11) in 2011 [42]. Unlike traditional swarm intelligence algorithms, the BSO algorithm is the first inspired by human behavior. By grouping, replacing and creating three kinds of operations, BSO simulates the group behavior of human beings in the problemsolving process to generate as many new individuals as possible, so as to gradually find the optimal individual from generation to generation. BSO optimizes the individual in parallel in each class to promote the local search, and promotes global search by jumping out of the local optimum through inter-class cooperation and mutation operations. The optimization process of the cluster center ensures the convergence performance of the algorithm, and the process of optimizing individual mutations in a class ensures the diversity of algorithm populations.

The following is the implementation process of BSO algorithm [43]:

Step 1: Randomly generate $n$ individuals in the target search space.

Step 2: Calculate the fitness function values of the $n$ individuals.

Step 3: The $n$ individuals are divided into $M$ classes by k-means clustering method.

Step 4: The individual who obtained the optimal fitness function value in each class was taken as the center of the class.

Step 5: Randomly select the central individual of a class, and the class center is updated with a certain probability $p_{a}$. Randomly generate a number $r_{1}$ between 0 and 1 , if $r_{1}<p_{a}$, then randomly generate an individual to replace the selected class center.

Step 6: Update the individual in the following four ways:

- Randomly select a class and add random disturbances to the class center to generate a new individual.

- Randomly select a class, select an individual at random in the selected class, and add a random disturbance to generate a new individual.

- Two classes are randomly selected, and two class centers are fused together with random disturbances to generate a new individual.

- Two classes are randomly selected, and each individual is randomly selected from each class to perform fusion, and a random disturbance is added to generate a new individual.
Suppose $p_{b}$ is the probability of adjusting the first two ways mentioned above to update the individual, and randomly generate a number $r_{2}$ between 0 and 1 . If $r_{2}<p_{b}$, then the individual is updated. Randomly generate a number $r_{3}$ between 0 and 1. $p_{m}$ stands for the probability that the individual in class $m$ is selected. If $r_{3}<p_{m}$, and $r_{3}<p_{c}$, update the individual in the manner (1). If $r_{3} \geq p_{c} r_{3} \geq p_{c}$, update the individual in the manner (2). If $r_{2} \geq p_{b}$, then randomly generate a number $r_{4}$ between 0 and 1 . If $r_{4}<p_{d}$, update the individual in the manner (3). If $r_{4} \geq p_{d}$, update the individual in the manner (4).

Step 7: Compare the fitness function values of the new individual with the original individual. If the new individual is superior, replace the original individual.

Step 8: Compare the individuals in the $M$ categories to find the individuals with the optimal fitness function value.

Step 9: Update the individual one by one. If the condition of iteration stop is met, stop the iteration. Otherwise, return to step 3 until the iteration is stopped.

Where the group is selected with a certain probability, and the probability that each group is selected is proportional to the number of individuals in this group.

For the generation of new individuals, it can be expressed as:

$$
x_{d}^{\text {new }}=x_{d}^{\text {selected }}+\xi \times N\left(\mu, \sigma^{2}\right)
$$

...where $x_{d}{ }^{n w e}$ is the d-dimensional component of the newly created individual; $x_{d}^{\text {selected }}$ is the d-dimensional component of the selected individual; $N\left(\mu, \sigma^{2}\right)$ is a normal distribution with a mean of $\mu$ and a variance of $\sigma^{2} ; \xi$ is a weight factor that can be expressed as:

$$
\xi=\log \operatorname{sig}[(0.5 \times T-t) / k] \times \operatorname{random}()
$$

...where the function of $\log \operatorname{sig}$ is a transfer function and the expression is $\log \operatorname{sig}(n)=\frac{1}{1+\exp (-n)} ; \quad T$ is the maximum number of iterations; $t$ is the current iterations; $k$ is used to change the slope of log $\operatorname{sig}(n)$; the function of random represents a random function between 0 and 1 .

The fusion process of two individuals can be expressed as:

$$
x^{n e w}=r x_{1}+(1-r) x_{2}
$$

...where $x^{\text {new }}$ is a new individual generated by the fusion of two individuals, $x_{1}$ and $x_{2}$ are two individuals performing the fusion operation, and $r$ is a random number between 0 and 1 .

The flow chart of BSO is as follows: 


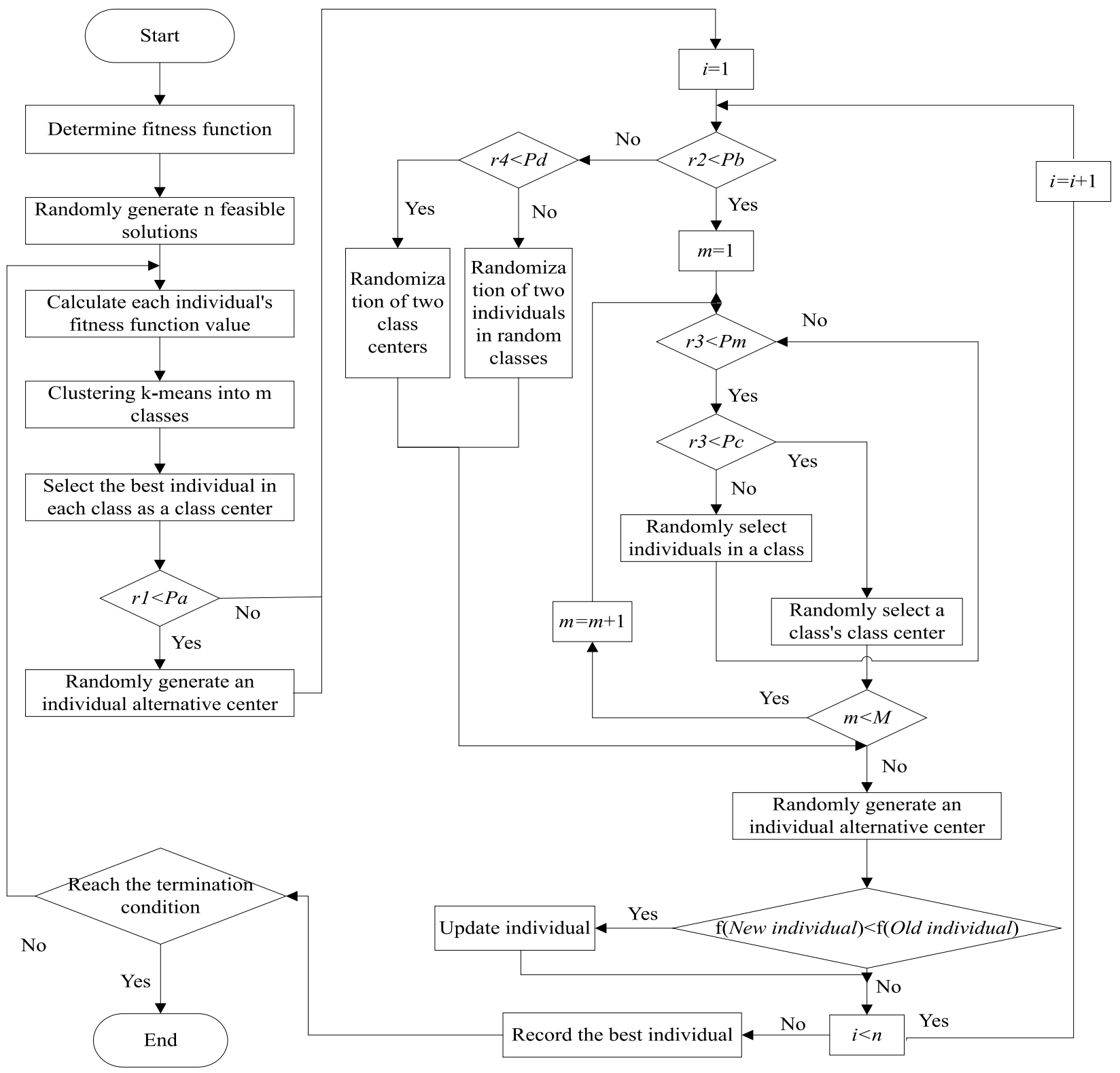

Fig. 2. Flow chart of BSO.

\section{Case Study}

In order to verify the validity and applicability of the low-carbon generation expansion planning model, this paper uses the basic situation of a certain region in the literature [47] as a data source, and optimizes the generation expansion planning problem in this region from 2018 to 2025 . The load forecast values during the planning period are shown in Table 1. The original unit parameters of the system are shown in Table 2. The planned unit parameters during the planning period are shown in Table 3. The construction period of the unit is ignored here. The load forecasting, wind power output and photovoltaic power output are represented by trapezoidal fuzzy parameters. The values of trapezoidal fuzzy membership parameters are shown in Table 4 . The quota indicators for each year during the planning period are shown in Table 5.
Table 1. Load forecast values during the planning period.

\begin{tabular}{|c|c|c|}
\hline Year & $\begin{array}{c}\text { Annual maximum } \\
\text { load } \\
\text { (MW) }\end{array}$ & $\begin{array}{c}\text { Annual electricity } \\
\text { consumption } \\
\text { (Billion } \mathrm{kWh})\end{array}$ \\
\hline 2018 & 2900 & 12 \\
\hline 2019 & 3190 & 13.2 \\
\hline 2020 & 3509 & 14.52 \\
\hline 2021 & 3860 & 15.97 \\
\hline 2022 & 4245.9 & 17.57 \\
\hline 2023 & 4670.5 & 19.33 \\
\hline 2024 & 5137.5 & 21.26 \\
\hline 2025 & 5651.3 & 23.38 \\
\hline
\end{tabular}


Table 2. Original unit parameters of the system.

\begin{tabular}{|c|c|c|c|c|c|}
\hline Type & Coal-fired unit A & Coal-fired unit B & Hydropower unit & Wind turbine & Photovoltaic plant \\
\hline Unit capacity (MW) & 300 & 600 & 100 & 100 & 20 \\
\hline Number of units & 3 & 3 & 2 & 2 & 6 \\
\hline Operating cost (RMB/kWh) & 317500 & 285600 & 65500 & 100500 & 120100 \\
\hline Carbon intensity (tonne/kWh) & 905 & 746 & 0 & 0 & 0 \\
\hline Annual utilization hours (h) & 6000 & 6000 & 3000 & 2400 & 2000 \\
\hline Minimum output coefficient & 0.75 & 0.75 & 0 & 0 & 0 \\
\hline Forced outage rate & 0.065 & 0.05 & 0.03 & 0.05 & 0.05 \\
\hline
\end{tabular}

Table 3. Planned unit parameters of the system.

\begin{tabular}{|c|c|c|c|c|c|}
\hline Type & Coal-fired unit A & Coal-fired unit B & Hydropower unit & Wind turbine & Photovoltaic plant \\
\hline Unit capacity (MW) & 300 & 600 & 100 & 100 & 20 \\
\hline Number of units & 3 & 6 & 6 & 5 & 12 \\
\hline Investment cost (million RMB) & 1122 & 2160 & 600 & 786.4 & 135.2 \\
\hline Operating cost (RMB/kWh) & 317500 & 285600 & 65500 & 100500 & 120100 \\
\hline Service life (year) & 25 & 25 & 30 & 20 & 25 \\
\hline Carbon intensity (tonne/kWh) & 905 & 746 & 0 & 0 & 0 \\
\hline Annual utilization hours (h) & 6000 & 6000 & 3000 & 2400 & 2000 \\
\hline Minimum output coefficient & 0.75 & 0.75 & 0 & 0 & 0 \\
\hline Forced outage rate & 0.065 & 0.05 & 0.03 & 0.05 & 0.05 \\
\hline
\end{tabular}

Table 4. Trapezoidal fuzzy parameters.

\begin{tabular}{|c|c|c|c|c|}
\hline Fuzzy parameter & $\omega_{1}$ & $\omega_{2}$ & $\omega_{3}$ & $\omega_{4}$ \\
\hline Load & 0.98 & 0.99 & 1.01 & 1.02 \\
\hline Wind power output & 0.96 & 0.98 & 1.02 & 1.04 \\
\hline Photovoltaic power output & 0.94 & 0.97 & 1.03 & 1.06 \\
\hline
\end{tabular}

Table 5. Parameters of renewable energy incentive mechanisms.

\begin{tabular}{|c|c|c|c|c|}
\hline Year & $\begin{array}{c}\text { Carbon price } \\
\text { (RMB/tonne) }\end{array}$ & $\begin{array}{c}\text { Green certificate price } \\
(\mathrm{RMB} / \text { base })\end{array}$ & $\begin{array}{c}\text { Carbon cap } \\
\text { (tonne/kWh) }\end{array}$ & $\begin{array}{c}\text { Renewable energy } \\
\text { quota }\end{array}$ \\
\hline 2018 & 35 & 20 & 750 & 0.18 \\
\hline 2019 & 35.42 & 20.24 & 740 & 0.19 \\
\hline 2020 & 35.85 & 20.48 & 720 & 0.20 \\
\hline 2021 & 36.28 & 20.73 & 690 & 0.21 \\
\hline 2022 & 36.71 & 20.98 & 680 & 0.24 \\
\hline 2023 & 37.15 & 21.23 & 660 & 0.25 \\
\hline 2024 & 37.60 & 21.48 & 650 & 0.26 \\
\hline 2025 & 38.05 & 21.74 & & \\
\hline
\end{tabular}


As shown in Table 4, due to the large variation of wind power and photovoltaic power output, their membership degree parameters have a large expansion range. The load forecasting is more accurate, so the expansion range is smaller. In Table 5, the initial carbon price is $35 \mathrm{RMB} / \mathrm{ton}$, the initial price of green certificate is $20 \mathrm{RMB} / \mathrm{base}$, and the expected growth rate is set to $1.2 \%$. The initial value of the renewable energy quota is 0.18 and the expected growth rate is set to $5 \%$. In addition, the carbon cap is $90 \%$ of the product between the power generation benchmark and the power generation under normal conditions of the enterprises, in which the power generation benchmark is $0.2 \%$ lower than the previous year, and the initial value of the carbon cap is 750 ton $/ \mathrm{kWh}$.

The relevant parameters are set as follows: the discount rate is $10 \%$, the fuzzy confidence level is $75 \%$, and each green certificate represents $1 \mathrm{MWh}$ of renewable energy generation. In recent years, the scale of wind power generation and photovoltaic power generation has been expanding, which has led to the technological advancement of the industry and the decline in material prices. It has also brought about a year-on-year decline in the investment cost of wind power and photovoltaic power generation. According to the International Energy Agency's (IEA) World Energy Outlook [48], the investment cost of photovoltaic plants is reduced by approximately $8.08 \%$ per year during the planning period, and the investment cost of wind turbines is reduced by approximately $0.38 \%$ per year. For the station service power consumption rate and the line loss rate, this paper takes the average value of them in recent years and remains unchanged during the planning period. After taking the average, the station service power consumption rates of thermal power, hydropower, wind power and photovoltaic power generation are: $7.67 \%, 2.57 \%, 3.67 \%, 2.01 \%$, and the line loss rate is $2.99 \%$.

\section{Comparing BSO with other Algorithms}

The BSO, PSO and GA are used to solve the low-carbon generation expansion planning model, respectively, and the experimental results of BSO are compared with that of PSO and GA to evaluate the effectiveness of the BSO algorithm. The experiments are performed using the MATLAB R2015a program. Each algorithm runs 30 times, and the optimal value of multiple runs is taken as the experimental result. In order to compare the performance of the various algorithms, the stopping criterion is set at same, the population size is 50 , and the maximum number of iterations is 500 . When solving with BSO, it is divided into five categories, and $P_{m}=0.1, P_{a}=0.5, P_{b}=0.5$, $P_{c}=0.3$, and $P_{d}=0.4$ are selected. For PSO, take $C_{1}=2$, $C_{2}^{c}=2$ and $\mathrm{W}$ starts at 1 and decreases until reaching 0 at the end of the run. Mutation rate $=0.7$ and crossover rate $=0.3$ are used to get the best results for GA.

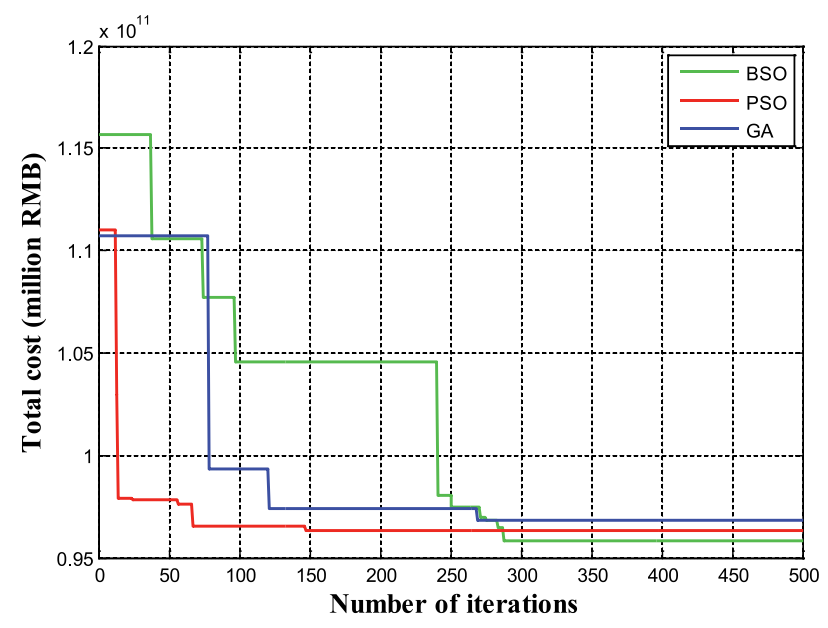

Fig. 3. Convergence characteristics of various optimization algorithms.

In order to compare the dynamic performance of the three swarm intelligence algorithms, the convergence characteristic curves of the three algorithms are given in Fig. 3. It can be seen that PSO and GA are constantly close to the optimal value in the early stage of searching, and the fitness value decreases rapidly in the first 80 generations. At this stage, PSO and GA mainly focus on finding feasible solutions to the problem. However, as the search goes on, the fitness value decreases slowly, and finally falls into local optimum and the result cannot be further optimized. For the BSO algorithm, the individuals keep approaching the minimum value after the search starts, and then there is a platform period when the individuals temporarily stagnate. When the individuals evolved to around 240 generations, the step size is sharply reduced by a relatively large value, causing the individuals to be reactivated and approached to a better position. The reason is that the individuals may have been close to an optimal position before 240 generations, but the excessive step size makes the individuals swing around to the optimal position. Therefore, when the step size decreases, the individuals slowly start to move toward the optimal position, and the result is further optimized. Thus, the adjustment of the step size plays a very important role in the effect of BSO algorithm, and the current step size strategy can make the BSO algorithm fully search for the global optimum.

Based on the experimental results given in Table 6, we can obtain the three swarm intelligence algorithms of BSO, PSO and GA in order to find the optimal fitness value of the low-carbon generation expansion planning model within a small number of iterations and the specified accuracy requirements. However, compared with PSO and GA, the BSO algorithm searches for the minimum economic cost. Therefore, the BSO algorithm performs best among the three algorithms to solve the low-carbon generation expansion planning problem. 
Table 6. Comparison of optimization algorithms.

\begin{tabular}{|c|c|c|c|c|c|c|}
\hline Algorithm & $\begin{array}{c}\text { Coal-fired A } \\
(\mathrm{MW})\end{array}$ & $\begin{array}{c}\text { Coal-fired B } \\
(\mathrm{MW})\end{array}$ & $\begin{array}{c}\text { Hydro } \\
(\mathrm{MW})\end{array}$ & $\begin{array}{c}\text { Wind } \\
(\mathrm{MW})\end{array}$ & $\begin{array}{c}\text { PV } \\
(\mathrm{MW})\end{array}$ & $\begin{array}{c}\text { Total cost } \\
\text { (million RMB) }\end{array}$ \\
\hline BSO & 300 & 3600 & 400 & 500 & 120 & 95798.42 \\
\hline PSO & 900 & 3000 & 600 & 200 & 180 & 96314.73 \\
\hline GA & 900 & 3000 & 600 & 300 & 120 & 96839.29 \\
\hline
\end{tabular}

\section{Results and Discussion}

\section{Results}

The proposed low-carbon generation expansion planning model considers the carbon trading mechanism and the green certificate transaction mechanism. This paper uses the BSO algorithm to solve the model, and the accumulated installed capacity of the new units in the planning period is shown in Fig. 4.

It can be seen that under the optimal planning scheme, the newly installed capacity of coal-fired unit A, coal-fired unit B, hydropower unit, wind turbine and photovoltaic plant during the planning period are $300 \mathrm{MW}, 3600 \mathrm{MW}, 400 \mathrm{MW}$, 500MW and $120 \mathrm{MW}$, respectively. In the initial stage of planning, in order to ensure the power demand of the system, coal-fired unit $A$ and coal-fired unit B are built under the condition of meeting carbon emission constraints. In the low-carbon situation, coal-fired unit A is gradually being phased out in planning due to its large carbon intensity. Meanwhile, in order to reduce the carbon trading cost and green certificate transaction cost, hydropower units with low operating cost and large annual utilization hours are prioritized. Due to the high operating cost and low annual utilization hours, the initial construction of wind turbines and photovoltaic plants is not very active.

With the strengthening of carbon cap constraint and renewable energy quota constraint, the system begins to build wind turbines and photovoltaic plants. Considering the high operating cost, the photovoltaic plant is not

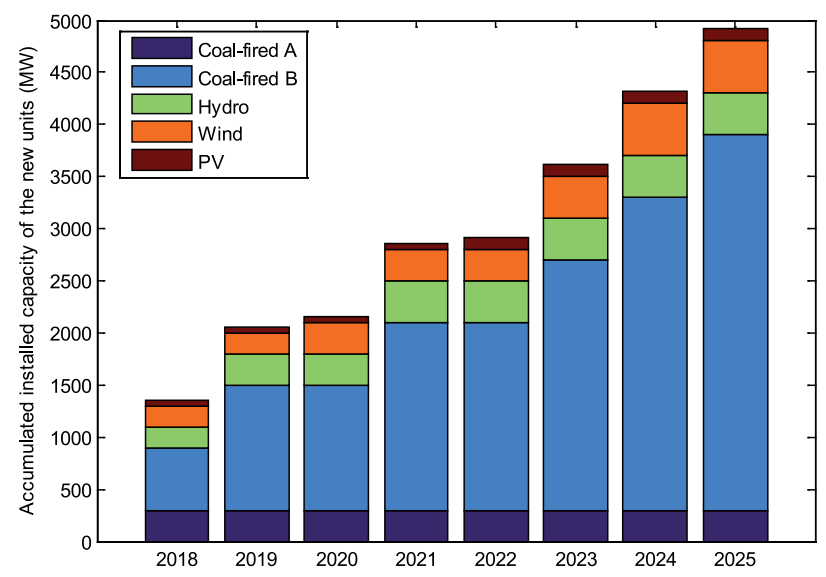

Fig. 4. Accumulated installed capacity of the new units during the planning period. competitive under the goal of minimizing the economic cost of the system, so its installed capacity is relatively small. At the same time, renewable energy power generation technology is still immature, so the system still needs to build some coal-fired B units with reliable operation and relatively low carbon intensity.

The discounted values of various costs during the planning period are shown in Table 7.

As can be seen from Table 7, in the initial stage of planning the system allows for a high carbon cap, and the renewable energy quota is relatively low. Therefore, the system can profit by selling carbon emission permits, and the green certificate transaction cost is small. With the gradual reduction of the carbon cap, since 2022 the system's carbon emissions have exceeded the allowable carbon emissions for that year, so it is necessary to purchase carbon emission permits to meet the carbon emissions limit. During the planning period, the proportion of renewable energy generation in the system has been lower than the government's prescribed ratio, so the system needs to purchase green certificates in order to meet the renewable energy quota. With the increase of green certificate price and renewable energy quota, the green certificate transaction cost to be paid by the system is increasing year by year. At the end of 2021, a large number of generator sets have been built, which can basically meet the demand for electricity consumption and maximum load in the system. Therefore, the system only invests $60 \mathrm{MW}$ of photovoltaic plants in 2022, and the investment cost is small, resulting in a small total cost in that year. In the following years, the operating cost, carbon trading cost and green certificate transaction cost are increasing year by year, resulting in an increase in the total cost.

\section{Discussion}

\section{Comparative Analysis}

In order to analyze the validity of the low-carbon generation expansion planning model proposed in this paper, the following four scenarios are set:

Scenario 1 (basic scenario): Carbon trading cost, green certificate transaction cost, carbon cap constraint and renewable energy quota constraint are not considered.

Scenario 2 (carbon trading scenario): Introduce the carbon trading mechanism into the basic scenario. 
Table 7. Costs during the planning period of the system.

\begin{tabular}{|c|c|c|c|c|c|}
\hline Year & $\begin{array}{c}\text { Total cost } \\
\text { (million RMB) }\end{array}$ & $\begin{array}{c}\text { Investment cost } \\
\text { (million RMB) }\end{array}$ & $\begin{array}{c}\text { Operating cost } \\
\text { (million RMB) }\end{array}$ & $\begin{array}{c}\text { Carbon trading cost } \\
\text { (million RMB) }\end{array}$ & $\begin{array}{c}\text { Green certificate transaction } \\
\text { cost (million RMB) }\end{array}$ \\
\hline 2018 & 13818.58 & 7230.73 & 6616.96 & -29.11 & 36.43 \\
\hline 2019 & 10652.86 & 3016.11 & 7664.77 & -28.01 & 50.68 \\
\hline 2020 & 8614.11 & 939.68 & 7688.89 & -14.45 & 53.08 \\
\hline 2021 & 11745.40 & 3016.11 & 8736.70 & -7.40 & 70.35 \\
\hline 2022 & 9226.90 & 462.71 & 8751.11 & 13.08 & 75.98 \\
\hline 2023 & 13150.69 & 3319.31 & 9803.39 & 28.00 & 105.06 \\
\hline 2024 & 14236.16 & 3319.31 & 10855.67 & 61.18 & 129.52 \\
\hline 2025 & 14353.73 & 2379.63 & 11883.83 & 90.27 & 160.13 \\
\hline
\end{tabular}

Scenario 3 (green certificate transaction scenario): Introduce the green certificate transaction mechanism into the basic scenario.

Scenario 4 (comprehensive scenario): The carbon trading mechanism and the green certificate transaction mechanism are introduced into the basic scenario, namely the low-carbon generation expansion planning model proposed in this paper.

The installed capacity of the four scenarios in the final year of planning are shown in Fig. 5. The key indicators of the four scenarios (converted to present value) are compared in Table 8.

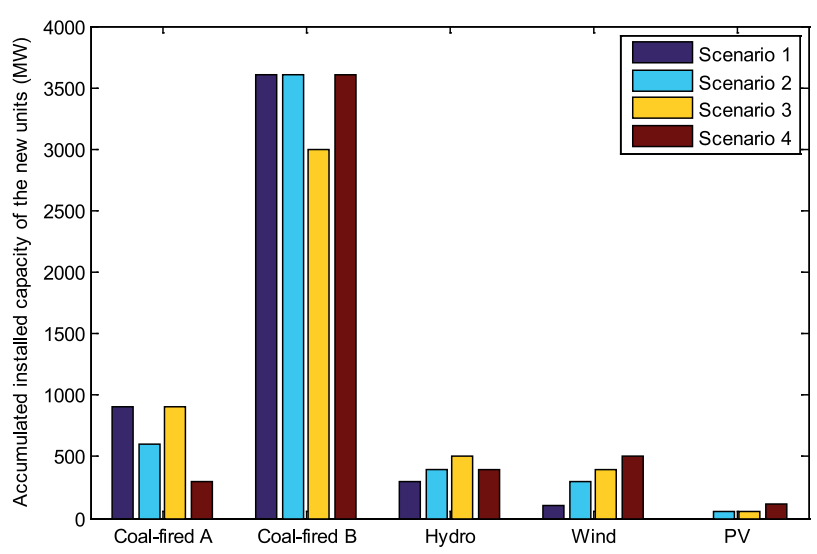

Fig 5. Installed capacity of the four scenarios in the final year of planning.
It can be seen from Fig. 5 that in the four scenarios, the installed proportion of renewable energy generator sets in the system is $8.16 \%, 15.32 \%, 19.75 \%$ and $20.73 \%$, respectively. The results show that the introduction of carbon trading mechanism and green certificate transaction mechanism can promote the development of renewable energy, and the promotion effect of the green certificate transaction mechanism is better than that of the carbon-trading mechanism. When the two mechanisms are introduced together, the installed proportion of renewable energy generator sets reached the highest, increasing by $12.57 \%$ over the basic scenario.

As can be seen from Table 8, the investment cost of renewable energy generator sets is higher than that of coal-fired units, and the operating cost is relatively low. Therefore, as the installed proportion of renewable energy generator sets increases, the investment cost of the system during the planning period gradually rises, while the operating cost decreases. The investment cost in the comprehensive scenario increased by $13.67 \%$ compared with the basic scenario, and the operating cost decreased by $8.13 \%$. When both the carbon trading mechanism and the green certificate transaction mechanism are introduced, they can play a mutually reinforcing role. The system's carbon trading cost and green certificate transaction cost are lower than when a single mechanism is introduced.

In addition, in the four scenarios, the total carbon emissions of the system are: 33.93 million tons,

Table 8 . Key indicators of the four scenarios.

\begin{tabular}{|c|c|c|c|c|c|c|}
\hline Type & $\begin{array}{c}\text { Total cost } \\
\text { (million RMB) }\end{array}$ & $\begin{array}{c}\text { Investment cost } \\
\text { (million RMB) }\end{array}$ & $\begin{array}{c}\text { Operating cost } \\
\text { (million RMB) }\end{array}$ & $\begin{array}{c}\text { Carbon trading } \\
\text { cost } \\
\text { (million RMB) }\end{array}$ & $\begin{array}{c}\text { Green certificate } \\
\text { transaction cost } \\
\text { (million RMB) }\end{array}$ & $\begin{array}{c}\text { Total carbon emis- } \\
\text { sion (million tonnes) }\end{array}$ \\
\hline Scenario 1 & 99211.71 & 20835.14 & 78376.57 & 0.00 & 0.00 & 33.94 \\
\hline Scenario 2 & 98605.66 & 22577.59 & 75706.14 & 321.93 & 0.00 & 32.32 \\
\hline Scenario 3 & 96577.47 & 23010.20 & 73567.27 & 0.00 & 799.87 & 31.26 \\
\hline Scenario 4 & 95798.42 & 23683.57 & 72001.30 & 113.56 & 681.24 & 30.69 \\
\hline
\end{tabular}


32.32 million tons, 31.26 million tons and 30.69 million tons, respectively. It can be seen that both the carbon trading mechanism and the green certificate trading mechanism can reduce the system's carbon emissions to some extent, and the optimization effect of the green certificate transaction mechanism is better than that of the carbon trading mechanism. When the carbon trading mechanism and green certificate transaction mechanism are jointly introduced, the total carbon emissions of the system reached a minimum that is 3.26 million tons lower than the basic scenario.

\section{Sensitivity Analysis}

1. Impact of different carbon prices on planning results On the basis of the benchmark scheme, the carbon trading price is reduced by $30 \%$ and increased by $30 \%$, respectively, to form a low carbon price scheme, a benchmark carbon price scheme and a high carbon price scheme. The difference in carbon trading prices leads to different generation expansion planning results. The accumulated installed capacity of the newly built units under the three schemes is shown in Fig. 6.

Fig. 6 shows that the change in the carbon price has a certain impact on the construction of units. In the low carbon price scheme, coal-fired units are built with priority due to their low operating cost, and their installed capacity accounts for $84.68 \%$ of the total installed capacity. Due to the intermittent, uncertain and costly investment of wind turbines and photovoltaic plants, their installed capacity is reduced. Later in the planning period, as the carbon emission limit is reduced, the system cannot guarantee that the carbon emissions are below the prescribed limit. However, at this time, the carbon price is relatively low, so the system chooses to purchase carbon emission permits instead of increasing the installed capacity of renewable energy units.

Under the high carbon price scheme, once the total carbon emissions of the system exceed the limit, the system will spend a high cost on the purchase

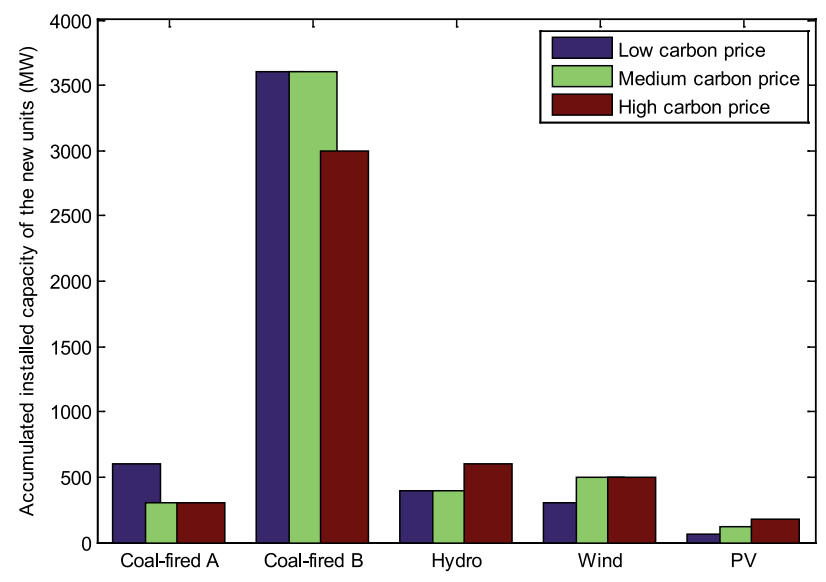

Fig. 6. Accumulated installed capacity of the new units under different carbon prices. of carbon emission permits. In this case, the system chooses to build wind turbines, hydropower units and photovoltaic plants. The construction of these three types of renewable energy units has effectively reduced the system's carbon emissions. At this time, the installed capacity of coal-fired units has fallen to $72.05 \%$ of the total installed capacity. As the carbon price rises, the system's carbon emissions continue to decrease, and the carbon emissions under the high carbon price scheme are reduced by 4.31 million tons compared to the low carbon price scheme. So, through increasing the carbon price, the development of renewable energy power generation can be promoted, thereby reducing the carbon emissions in the system.

2. Impact of different carbon caps on planning results.

On the basis of the benchmark scheme, the carbon cap is reduced by $30 \%$ and increased by $30 \%$, respectively. Three generation expansion planning schemes with different carbon emission constraints are obtained. The accumulated installed capacity of the newly built units under the three schemes is shown in Fig. 7.

Similar to adjusting the carbon price, changing the carbon cap also has a significant impact on the planning results. When the carbon cap is increased by $30 \%$, the carbon trading cost saved by the renewable energy generator sets is not enough to make up for the investment cost of the new renewable energy units. Therefore, the system chooses to prioritize the construction of coal-fired units. Compared with the benchmark carbon cap scheme, the newly installed capacity of hydropower units, wind turbines and photovoltaic plants has declined. As carbon emission limits increase, the system is increasingly investing in renewable energy generator sets to reduce the carbon trading cost.

When the carbon cap is reduced by $30 \%$, the system builds a new hydropower unit and three photovoltaic plants to replace the coal-fired unit A. Therefore, with the strengthen of carbon cap constraint, the installed proportion of coal-fired units will gradually decrease,

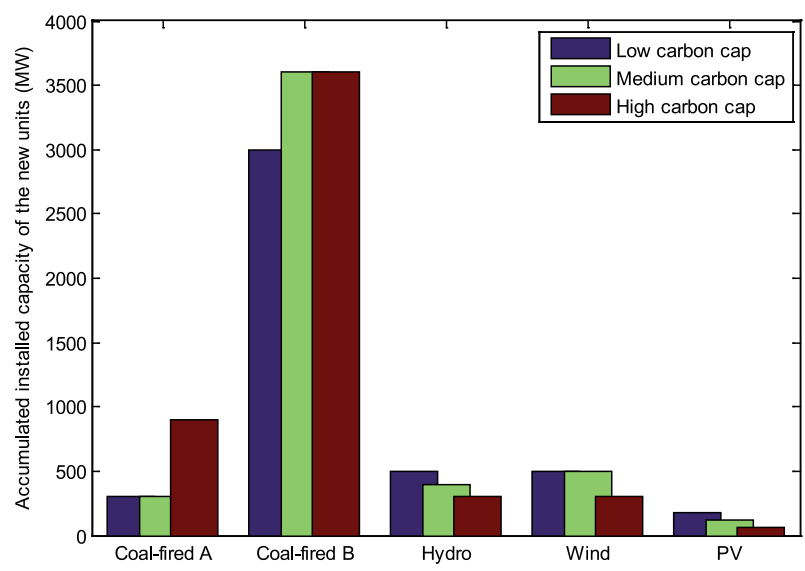

Fig. 7. Accumulated installed capacity of the new units under different carbon caps. 


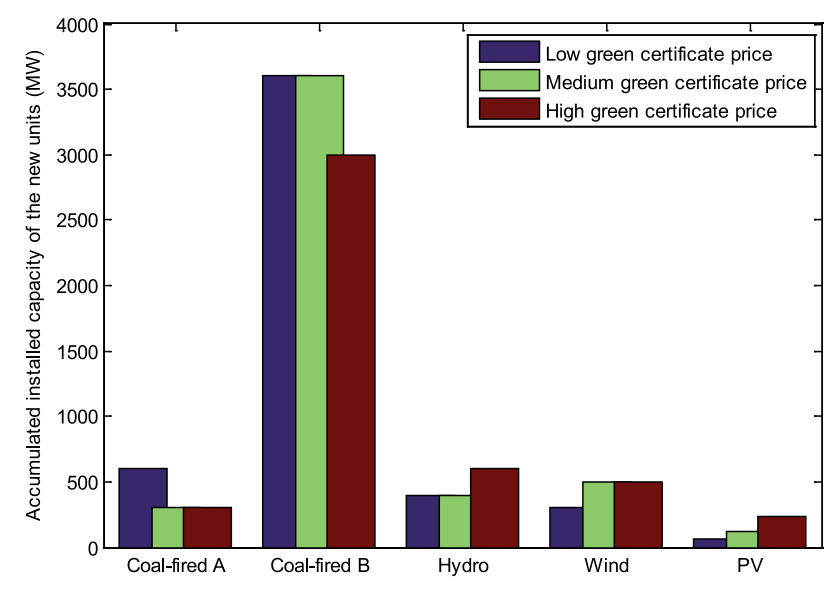

Fig. 8. Accumulated installed capacity of the new units under different green certificate prices.

but hydropower units, wind turbines and photovoltaic plants will gradually be built due to their zero-emission characteristics. In addition, the carbon emissions under the low carbon cap scheme are reduced by 5.94 million tons compared to the high carbon cap scheme. Therefore, by reducing carbon cap, renewable energy generation can be promoted, thereby reducing the carbon emissions of the system.

3. Impact of different green certificate prices on planning results.

On the basis of the benchmark scheme, the green certificate price is reduced by $30 \%$ and increased by $30 \%$, respectively, to form three schemes. The accumulated installed capacity of the newly built units under the three schemes is shown in Fig. 8.

Fig. 8 shows that under the low green certificate price scheme, the government has a low renewable energy quota in the early stage of planning period. The system can meet the quotas specified by purchasing a small amount of green certificates. With the increase of renewable energy quotas, the number of green certificates that the system needs to purchase has also increased year by year. However, the green certificate price is low, the system chooses to buy green certificates instead of investing in renewable energy generator sets. At this time, the installed capacity of renewable energy generator sets only accounts for $15.32 \%$ of the total installed capacity.

With the increase in the price of green certificates, the system gradually begins to build renewable energy units. The installed capacity of renewable energy units in the high green certificate price scheme further increased to $28.88 \%$. In addition, the carbon emissions under the high certificate price scheme have been reduced by 5.94 million tons compared to the low price scheme. Therefore, by increasing the green certificate price, the development of renewable energy power generation can be promoted, and the carbon emissions of the system can be further reduced.

4. Impact of different renewable energy quotas on planning results.

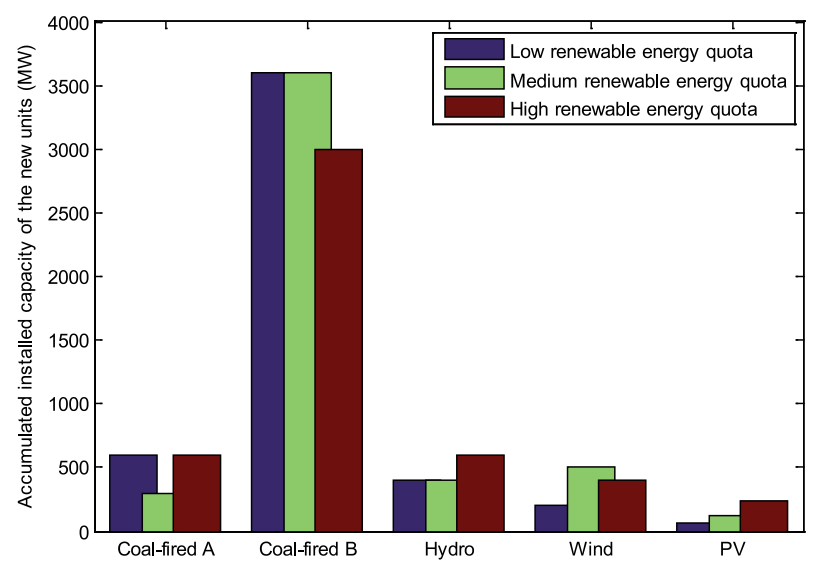

Fig. 9. Accumulated installed capacity of the new units under different renewable energy quotas.

On the basis of the benchmark scheme, the renewable energy quota is reduced by $30 \%$ and increased by $30 \%$, respectively, to form three different schemes. The accumulated installed capacity of the newly built units under the three schemes is shown in Fig. 9.

Fig. 9 shows that under the low renewable energy quota scheme, the government has a low renewable energy quota in the early stage of planning, and the system can complete the quota indicator by purchasing a small amount of green certificates. Therefore, it is preferred to invest in coal-fired units with low operating cost, while the number of newly built renewable energy generator sets is small. In the later stage of planning, with the increase of renewable energy quota, the green certificate cost paid by the system has also increased year by year. Unlike the benchmark quota scheme, the system chooses to purchase green certificates to guarantee the renewable energy quota target instead of investing in renewable energy units. This is because the cost of purchasing green certificates for the system is lower than the cost of building renewable energy generator sets.

Under the high quota scheme, the system can save many green certificate transaction costs by renewable energy power generation. Therefore, the system has invested a large number of hydropower units, wind turbines and photovoltaic plants in the initial planning period. The generating capacity of these three types of units guarantees the renewable energy quota targets. In addition, with the increase in renewable energy quota, the total carbon emissions under the high quota scheme is reduced by 2.69 million tons compared to the low quota scheme. Therefore, increasing the renewable energy quota can promote the development of renewable energy, thereby reducing the system's carbon emissions.

\section{Conclusions}

With the increasingly serious environmental problems, the traditional generation expansion 
planning can no longer meet the requirements of social development, and gradually shift to a lowcarbon direction. This paper introduces the carbon trading mechanism and the green certificate transaction mechanism into the traditional generation expansion planning, and establishes a low-carbon generation expansion planning model with the minimum economic cost as the objective function. Then, fuzzy chance constraints are used to transform the load forecasting, wind power output and photovoltaic power output of these uncertain factors into their clear equivalence classes. Finally, this paper uses the BSO algorithm to solve the model, and the feasibility of the model is verified by a case. In this case, the basic scenario, carbon trading scenario, green certificate transaction scenario and comprehensive scenario are compared. And the impacts of different carbon prices, carbon caps, green certificate prices and renewable energy quotas on the planning results are analyzed. Our main conclusions are as follows:

(1) Both the carbon trading mechanism and the green certificate transaction mechanism can promote the development of renewable energy, and reduce the carbon emissions in the power sector.

(2) The optimization effect of the green certificate transaction mechanism is better than that of the carbon trading mechanism. When both mechanisms are introduced, the system has the highest installed proportion of renewable energy and the lowest total carbon emissions.

(3) With the increase of carbon price or green certificate price, and the strengthening of carbon cap constraint or renewable energy quota constraint, the proportion of renewable energy units is gradually increasing, and the total carbon emissions of the system are gradually reduced.

These conclusions have guiding significance for implementing the carbon trading and green certificate transaction mechanisms in the power sector, and provide a reference for the formulation of carbon price, carbon cap, green certificate price and renewable energy quota, thus promoting the low-carbon development of the power industry.

\section{Acknowledgements}

The authors would like to thank the support of the Fundamental Research Funds for the Central Universities (grant No. 2018QN095).

\section{Conflict of Interest}

The authors declare no conflict of interest.

\section{References}

1. IPCC (Intergovernmental Panel on Climate Change). The IPCC Fifth Assessment Report 2014. Available online: http://www.ipcc.ch/ (accessed on 21/10/2018).

2. National Development and Reform Commission. National Climate Change Program (2014-2020). Available online: http://www.ndrc.gov.cn/zcfb/zcfbtz/201411/ W020141104584717807138.pdf (accessed on 21/10/2018). [In Chinese].

3. ZHANG L., JIANG Z., LIU R., TANG M., WU F. Can China achieve its $\mathrm{CO}_{2}$ emission mitigation target in 2030: A system dynamics perspective. Pol. J. Environ. Stud., 27 (6), 2861, 2018.

4. BOLUK G., MERT M. Fossil and renewable energy consumption, GHGs (greenhouse gases) and economic growth: Evidence from a panel of EU (European Union) countries. Energy, 60, 1, 2014.

5. PARK K., SHIN D., YOON E.S. The cost of energy analysis and energy planning for emerging, fossil fuel power plants based on the climate change scenarios. Energy, 36 (5), 3606, 2011.

6. ZHOU Y., LI Y.P., HUANG G.H. Planning sustainable electric-power system with carbon emission abatement through CDM under uncertainty. Appl. Energy, 140, 350, 2015.

7. SADEGHI H., RASHIDINEJAD M., ABDOLLAHI A. A comprehensive sequential review study through the generation expansion planning. Renewable Sustainable Energy Rev., 67, 1369, 2017.

8. FATHTABAR H., BARFOROUSHI T., SHAHABI M. Dynamic long-term expansion planning of generation resources and electric transmission network in multicarrier energy systems. International Journal of Electrical Power \& Energy Systems, 102, 97, 2018.

9. TROTTER P.A., MACONACHIE R., MCMANUS M.C. Solar energy's potential to mitigate political risks: The case of an optimised Africa-wide network. Energy Policy, 117, 108, 2018.

10. TEKINER H., COIT D.W., FELDER F.A. Multi-period multi-objective electricity generation expansion planning problem with Monte-Carlo simulation. Electr. Power Syst. Res., 80(12), 1394, 2010.

11. LI S., COIT D.W., FELDER F. Stochastic optimization for electric power generation expansion planning with discrete climate change scenarios. Electr. Power Syst. Res., 140, 401, 2016.

12. SHIVAIE M., AMELI M.T. A stochastic framework for multi-stage generation expansion planning under environmental and techno-economic constraints. Electric Machines \& Power Systems, 44 (17), 18, 2016.

13. JAYAPALAN B., KRISHNAN M., KANDASAMY K., SUBRAMANIAN K. Renewable energy penetration and its impact on reliability - a case study of Tamil Nadu. J. Comput. Theor. Nanosci., 14 (8), 4036, 2017.

14. GITIZADEH M., KAJI M., AGHAEI J. Risk based multiobjective generation expansion planning considering renewable energy sources. Energy, 50 (1), 74, 2013.

15. AGHAEI J., AKBARI M.A., ROOSTA A., GITIZADEH M. Integrated renewable-conventional generation expansion planning using multiobjective framework. Iet Generation Transmission \& Distribution, 6 (8), 773, 2012.

16. JAIN N., SINGH S.N., SRIVASTAVA S.C. PSO based placement of multiple wind DGs and capacitors utilizing 
probabilistic load flow model. Swarm \& Evolutionary Computation, 19, 15, 2014.

17. KAABECHE A., IBTIOUEN R. Techno-economic optimization of hybrid photovoltaic/ wind/ diesel/ battery generation in a stand-alone power system. Solar Energy, 103, 171, 2014.

18. ZHANG L., ZENG Y., LI D. China's emissions trading scheme: First evidence on pilot stage. Pol. J. Environ. Stud., 28 (2), 543, 2019.

19. ZHAO X.G., JIANG G.W., DAN N., HAO C. How to improve the market efficiency of carbon trading: A perspective of China. Renewable Sustainable Energy Rev., 59, 1229, 2016.

20. DONG F., HAN Y., DAI Y., LONG R., YU B. How carbon emission quotas can be allocated fairly and efficiently among different industrial sectors: The case of Chinese industry. Pol. J. Environ. Stud., 27 (6), 2883, 2018.

21. LING X., BO S., QI S., PRICE L., YE B. The allowance mechanism of China's carbon trading pilots: A comparative analysis with schemes in EU and California. Appl. Energy, 185, 1849, 2017.

22. BERGEK A., JACOBSSON S. Are tradable green certificates a cost-efficient policy driving technical change or a rent-generating machine? Lessons from Sweden 20032008. Energy Policy, 38 (3), 1255, 2010.

23. GHAFFARI M., HAFEZALKOTOB A., MAKUI A. Analysis of implementation of tradable green certificates system in a competitive electricity market: A game theory approach. Journal of Industrial Engineering International, 12 (2), 185, 2016.

24. CHEN C., ZHU Y., ZENG X., HUANG G., LI Y. Analyzing the carbon mitigation potential of tradable green certificates based on a TGC-FFSRO model: A case study in the Beijing-Tianjin-Hebei region, China. Sci. Total Environ., 630, 469, 2018.

25. WEDZIK A., SIEWIERSKI T., SZYPOWSKI M. Green certificates market in Poland-The sources of crisis. Renewable Sustainable Energy Rev., 75, 490, 2017.

26. ZHU Y., LI Y.P., HUANG G.H., FAN Y.R., NIE S. A dynamic model to optimize municipal electric power systems by considering carbon emission trading under uncertainty. Energy, 88, 636, 2015.

27. ZHU Y., LI Y.P., HUANG G.H. An optimization decision support approach for risk analysis of carbon emission trading in electric power systems. Environmental Modelling \& Software, 67, 43, 2015.

28. UNSIHUAY-VILA C., MARANGON-LIMA J.W., SOUZA A.C.Z.D., PEREZ-ARRIAGA I.J. Multistage expansion planning of generation and interconnections with sustainable energy development criteria: A multiobjective model. International Journal of Electrical Power \& Energy Systems, 33 (2), 258, 2011.

29. TAN Z.F., SONG Y.H., SHEN Y.S. An optimization-based study to analyze the impacts of clean energy and carbon emission mechanisms on inter-regional energy exchange. Journal of Environmental Informatics, 22, 23, 2013.

30. BERGEK A., JACOBSSON S. Are tradable green certificates a cost-efficient policy driving technical change or a rent-generating machine? Lessons from Sweden 20032008. Energy Policy, 38 (3), 1255, 2010.

31. QIN Y.H., YANG W. Analysis of the positive role of green certificate transaction mechanism in the development of renewable energy. Financial Economy, 6, 93, 2009.
32. PARK H., BALDICK R. Multi-year stochastic generation capacity expansion planning under environmental energy policy. Appl. Energy, 183, 737, 2016.

33. GEEM Z.W., KIM J.H. Optimal energy mix with renewable portfolio standards in Korea. Sustainability, 8, 423, 2016.

34. PEREIRA A.J.C., SARAIVA J.T. Generation expansion planning (GEP) - A long-term approach using system dynamics and genetic algorithms (GAs). Energy, 36 (8), 5180, 2011.

35. MARKUS L., MAGNUS K. Hydro power reservoir aggregation via genetic algorithms. Energies, 10, 2165, 2017.

36. NICOLAS K.B., FERNANDO P.A. Realistic wind farm layout optimization through genetic algorithms using a Gaussian wake model. Energies, 11, 3268, 2018.

37. GANGULY S., SAHOO N.C., DAS D. Mono- and multiobjective planning of electrical distribution networks using particle swarm optimization. Applied Soft Computing, 11 (2), 2391, 2011

38. HAKIMI S.M., MOGHADDAS-TAFRESHI S.M. Optimal sizing of a stand-alone hybrid power system via particle swarm optimization for Kahnouj area in south-east of Iran. Renewable Energy, 34 (7),1855, 2009.

39. El-ZONKOLY A.M. Optimal placement of multidistributed generation units including different load models using particle swarm optimisation. Iet Generation Transmission \& Distribution, 1 (1), 50, 2011.

40. AGHAEI J., MUTTAQI K.M., AZIZIVAHED A., GITIZADEH M. Distribution expansion planning considering reliability and security of energy using modified PSO (Particle Swarm Optimization) algorithm. Energy, 65, 398, 2014.

41. HEMMATI R., SABOORI H., JIRDEHI M.A. Multistage generation expansion planning incorporating large scale energy storage systems and environmental pollution. Renewable Energy, 97, 636, 2016.

42. SHI Y.H. Brain storm optimization algorithm. Advances in Swarm Intelligence, 6728, 303, 2011.

43. SHI Y.H. An optimization algorithm based on brainstorming process. International Journal of Swarm Intelligence Research, 2, 35, 2011.

44. CHEN F., HUANG G.H., FAN Y.R., CHEN J.P. A copulabased fuzzy chance-constrained programming model and its application to electric power generation systems planning. Appl. Energy, 187, 291, 2017.

45. FAN S., QIAN A., PIAO L. Fuzzy day-ahead scheduling of virtual power plant with optimal confidence level. Iet Generation Transmission \& Distribution, 10 (1), 205, 2016.

46. GUPTA P., INUIGUCHI M., MEHLAWAT M.K., MITTAL G. Multiobjective credibilistic portfolio selection model with fuzzy chance-constraints. Information Sciences, 229 (229), 1, 2013.

47. ZHANG X.H., YAN D.P., ZHONG J.Q., LU Z.G. Research on generation expansion planning in low-carbon economy environment under incentive mechanism of renewable energy sources. Power System Technology, 39 (3), 655, 2015.

48. IEA (International Energy Agency). World Energy Outlook 2018. Available online: https://www.iea.org/ weo2018/ (accessed on 16/12/2018). 
